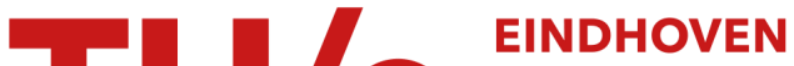 UNIVERSITY OF TECHNOLOGY
}

\section{On a recursive formula for the moments of phase noise}

Citation for published version (APA):

Tafur Monroy, I., \& Hooghiemstra, G. (2000). On a recursive formula for the moments of phase noise. IEEE Transactions on Communications, 48(6), 917-920. https://doi.org/10.1109/26.848548

DOI:

10.1109/26.848548

Document status and date:

Published: 01/01/2000

\section{Document Version:}

Publisher's PDF, also known as Version of Record (includes final page, issue and volume numbers)

\section{Please check the document version of this publication:}

- A submitted manuscript is the version of the article upon submission and before peer-review. There can be important differences between the submitted version and the official published version of record. People interested in the research are advised to contact the author for the final version of the publication, or visit the $\mathrm{DOI}$ to the publisher's website.

- The final author version and the galley proof are versions of the publication after peer review.

- The final published version features the final layout of the paper including the volume, issue and page numbers.

Link to publication

\section{General rights}

Copyright and moral rights for the publications made accessible in the public portal are retained by the authors and/or other copyright owners and it is a condition of accessing publications that users recognise and abide by the legal requirements associated with these rights.

- Users may download and print one copy of any publication from the public portal for the purpose of private study or research.

- You may not further distribute the material or use it for any profit-making activity or commercial gain

- You may freely distribute the URL identifying the publication in the public portal.

If the publication is distributed under the terms of Article $25 \mathrm{fa}$ of the Dutch Copyright Act, indicated by the "Taverne" license above, please follow below link for the End User Agreement:

www.tue.nl/taverne

Take down policy

If you believe that this document breaches copyright please contact us at:

openaccess@tue.nl

providing details and we will investigate your claim. 


\title{
On a Recursive Formula for the Moments of Phase Noise
}

\author{
Idelfonso Tafur Monroy and Gerard Hooghiemstra
}

\begin{abstract}
In this paper, we present a recursive formula for the moments of phase noise in communication systems. The phase noise is modeled using continuous Brownian motion. The recursion is simple and valid for an arbitrary initial phase value. The moments obtained by the recursion are used to calculate approximations to the probability density function of the phase noise, using orthogonal polynomial series expansions and a maximum entropy criterion.
\end{abstract}

Index Terms-Brownian motion, derivation of moments, error analysis, maximum entropy, optical communication, phase noise.

\section{INTRODUCTION}

$\mathbf{P}$ HASE noise has proven to be a major performance-limiting factor in a number of communication systems. For example, in optical coherent or weakly coherent systems, e.g., [1], [2]. Multicarrier transmission, using orthogonal frequency-division multiplexing, for instance in wireless indoor systems, is very sensitive to phase noise [3], [4]. Phase noise is also reported to degrade the performance of coherent analog amplitude-modulated wide-band rectifier narrow-band optical links [5], among others. The statistical properties of phase noise (in the context of optical communication systems) have been studied by several authors, e.g., [1] and [2] and by those authors to whom they refer. It is a complex problem for which different types of approximate solutions have been presented (cf. [2]). The authors in [1] use simulation techniques; a characterization through moments has been given by [6] and [7], whereas a numerical approach is given in [8]. The list of references on phase noise analysis cited here is by no means complete but demonstrates the range of different approaches.

From a mathematical point of view, characterizing phase noise is equivalent to the study of the complex-valued stochastic process (cf. [1])

$$
Z_{x}(t)=\int_{0}^{t} e^{j(x+B(s))} d s, \quad t \geq 0
$$

where $\{B(s), s \geq 0\}$ is Brownian motion starting from 0, with zero mean and variance

$$
\sigma_{s}^{2}=\operatorname{var}(B(s))=\beta s .
$$

The parameter $\beta=2 \pi \Delta \nu$, where $\Delta \nu$ is the Lorentz linewidth of the oscillator (laser linewidth in the case of optical systems).

Paper approved by J. J. O'Reilly, the Editor for Optical Communications of the IEEE Communications Society. Manuscript received June 3, 1998; revised January 20, 1999.

I. T. Monroy is with the Department of Telecommunications Technology and Electromagnetics, Eindhoven University of Technology, 5600 MB Eindhoven, The Netherlands (e-mail: i.tafur@tue.nl).

G. Hooghiemstra with the Department of Statistics, Probability and Operations Research, Delft University of Technology, 2600 GA Delft, The Netherlands.

Publisher Item Identifier S 0090-6778(00)05408-8.
The process $\left\{Z_{x}(t), t \geq 0\right\}$ can be decomposed into its real and imaginary part

$$
\begin{aligned}
Z_{x}(t) & =\int_{0}^{t} \cos (x+B(s)) d s+j \int_{0}^{t} \sin (x+B(s)) d s \\
& =X_{x}(t)+j Y_{x}(t) .
\end{aligned}
$$

We present a recursive formula, (8), for the moments of $X_{x}(t)$ and $Y_{x}(t)$, for fixed $t \geq 0$. The recursion has two advantages over the one given in [6]. It is simpler in form, and it is valid for arbitrary initial value $x \in \mathbb{R}$ of Brownian motion $\{B(s)$, $s \geq 0\}$, whereas the recursion of [6] is restricted to the initial value $x=0$.

We close the section with a definition and some notation. We denote by $P_{x}$ the probability measure of the Brownian motion starting from $x \in \mathbb{R}$. More specifically for each Borel set $A$, consisting of continuous functions on $[0, \infty)$

$$
P_{x}\left((B(s))_{s \geq 0} \in A\right)=P\left((x+B(s))_{s \geq 0} \in A\right)
$$

where $P=P_{0}$ is the probability measure of Brownian motion $\{B(s), s \geq 0\}$, starting from 0 . The symbol $E_{x}$ is used for the mathematical expectation with respect to the probability measure $P_{x}$. Note that the $P_{x}$ distribution of $Z_{0}$ is equal to the $P_{0}$ distribution of $Z_{x}$. When we write $Z, X$, or $Y$ without subscript, we mean $Z_{0}, X_{0}$, or $Y_{0}$, respectively. Finally, we often write $B_{s}$ instead of $B(s)$.

\section{RECURSIVE FORMULA}

We consider the following functional of the Brownian motion:

$$
A_{t}=A_{t}\left(\left(B_{s}\right)_{s \geq 0}\right)=\int_{0}^{t} f\left(B_{s}\right) d s, \quad t \geq 0
$$

where $f$ is a measurable, nonnegative function. Moreover, for some $\lambda>0$ the function $f$ should satisfy

$$
\int_{-\infty}^{\infty} f(y) e^{-|y| \sqrt{\lambda}} d y<\infty .
$$

Denote for fixed $t$, by $E_{x} e^{-b A_{t}}, b>0$, the Laplace-Stieltjes transform of the random variable $A_{t}$. We first derive from a simplified form of the Feynman-Kac formula (cf. [9, p. 272]) a functional equation for the double Laplace transform

$$
\int_{0}^{\infty} e^{-\lambda t} E_{x} e^{-b A_{t}} d t, \quad \lambda, b>0
$$

of the random variable $A_{t}$. From this functional equation, the moment recursion (8), which is surprisingly simple, follows.

Observe that

$$
A_{t}=\int_{0}^{t} f\left(B_{s}\right) d s
$$


is a so-called additive functional

$$
A_{s+u}-A_{s}=A_{u} \circ \theta_{s}
$$

where $\theta_{s}$ is the shift operator $\left(\theta_{s}\right.$ maps the set of continuous functions on $[0, \infty)$ onto the set of the continuous functions on $[0, \infty)$ and is defined by $\theta_{s}(g)(u)=g(s+u)$, where $g$ is a continuous function on $[0, \infty)$ ). The proof that $\left\{A_{t}, t \geq 0\right\}$ is additive is straightforward

$$
\begin{aligned}
A_{s+u}-A_{s} & =\int_{0}^{s+u} f\left(B_{v}\right) d v-\int_{0}^{s} f\left(B_{v}\right) d v \\
& =\int_{s}^{s+u} f\left(B_{v}\right) d v=\int_{0}^{u} f\left(B_{s+v}\right) d v \\
& =\int_{0}^{u} f\left(\theta_{s}\left(B_{v}\right)\right) d v=A_{u} \circ \theta_{s}
\end{aligned}
$$

where it is implicitly assumed that both sides $A_{s+u}-A_{s}$ and $A_{u} \circ \theta_{s}$ are applied to the random continuous function $\{B(v), v \geq 0\}$.

Following [9, p. 272], we obtain for $\lambda, b>0$

$$
\begin{aligned}
& E_{x} \int_{0}^{\infty} e^{-\lambda t-b A_{t}}\left(e^{b A_{t}}-1\right) d t \\
& \quad=E_{x} \int_{0}^{\infty} e^{-\lambda t-b A_{t}}\left\{\int_{0}^{t} b f\left(B_{s}\right) e^{b A_{s}} d s\right\} d t \\
& \quad=E_{x} \int_{0}^{\infty} e^{-\lambda s} b f\left(B_{s}\right)\left\{\int_{s}^{\infty} e^{-\lambda(t-s)-b\left(A_{t}-A_{s}\right)} d t\right\} d s \\
& \quad=E_{x} \int_{0}^{\infty} e^{-\lambda s} b f\left(B_{s}\right)\left\{\int_{0}^{\infty} e^{-\lambda u-b A_{u} \circ \theta_{s}} d u\right\} d s \\
& =E_{x} \int_{0}^{\infty} e^{-\lambda s} b f\left(B_{s}\right) E_{B_{s}}\left\{\int_{0}^{\infty} e^{-\lambda u-b A_{u}} d u\right\} d s
\end{aligned}
$$

Here, the first equality sign follows from

$$
\frac{d}{d s} e^{b A_{s}}=b f\left(B_{s}\right) e^{b A_{s}}
$$

which implies

$$
\int_{0}^{t} b f\left(B_{s}\right) e^{b A_{s}} d s=e^{b A_{t}}-1
$$

Changing the order of integration (this is permitted by Fubini's theorem since the integrand is nonnegative) yields the third line. The third equality is justified by a change of variables $u=t-s$, and by

$$
A_{t}-A_{s}=A_{s+u}-A_{s}=A_{u} \circ \theta_{s}
$$

where we use the additivity of the functional $\left\{A_{t}, t \geq 0\right\}$. Finally, the last equality is the (weak) Markov property (see [9] or Freedman [10]). The Brownian motion starts afresh from position $B_{s}$.

Define

$$
\phi_{b}(x, \lambda)=\int_{0}^{\infty} e^{-\lambda t} E_{x} e^{-b A_{t}} d t
$$

The left-hand side of (5) can be written as

$$
\begin{aligned}
E_{x} & \int_{0}^{\infty} e^{-\lambda t-b A_{t}}\left(e^{b A_{t}}-1\right) d t \\
& =\int_{0}^{\infty} e^{-\lambda t} d t-\int_{0}^{\infty} e^{-\lambda t} E_{x} e^{-b A_{t}} d t \\
& =\frac{1}{\lambda}-\phi_{b}(x, \lambda)
\end{aligned}
$$

and the right-hand side as

$$
\begin{aligned}
E_{x} \int_{0}^{\infty} e^{-\lambda s} b f\left(B_{s}\right) E_{B_{s}}\left\{\int_{0}^{\infty} e^{-\lambda u-b A_{u}} d u\right\} d s \\
\quad=\int_{0}^{\infty} e^{-\lambda s} \int_{-\infty}^{\infty} b f(y) \phi_{b}(y, \lambda) \frac{e^{-(y-x)^{2} / 2 \sigma_{s}^{2}}}{\sigma_{s} \sqrt{2 \pi}} d s d y \\
\quad=b \int_{-\infty}^{\infty} f(y) \phi_{b}(y, \lambda) \int_{0}^{\infty} e^{-\lambda s} \frac{e^{-(y-x)^{2} / 2 \sigma_{s}^{2}}}{\sigma_{s} \sqrt{2 \pi}} d y d s \\
=b \int_{-\infty}^{\infty} \phi_{b}(y, \lambda) f(y) \frac{e^{-|y-x| \sqrt{2 \lambda / \beta}}}{\sqrt{2 \lambda \beta}} d y .
\end{aligned}
$$

Hence, we get the functional equation

$$
\frac{1}{\lambda}-\phi_{b}(x, \lambda)=b \int_{-\infty}^{\infty} \phi_{b}(y, \lambda) f(y) \frac{e^{-|y-x| \sqrt{2 \lambda / \beta}}}{\sqrt{2 \lambda \beta}} d y .
$$

By expanding on both sides of (6) the expression $e^{-b A_{t}}$ in a power series in $b \in(0,1)$ and comparing the coefficients of $b^{n}$, we obtain

$$
\begin{aligned}
& \int_{0}^{\infty} e^{-\lambda t} E_{x} A_{t}^{n} d t= \\
& \quad n \int_{-\infty}^{\infty} f(y) \int_{0}^{\infty} \frac{e^{-\lambda s-|y-x| \sqrt{2 \lambda / \beta}}}{\sqrt{2 \lambda \beta}} E_{y} A_{s}^{n-1} d s d y .
\end{aligned}
$$

A recursive formula for $E_{x} A_{t}^{n}$ can be obtained by taking on both sides of the above equation the inverse Laplace transform. Note that the inverse Laplace transform of

$$
\frac{e^{-\lambda s-|y-x| \sqrt{2 \lambda / \beta}}}{\sqrt{2 \lambda \beta}}
$$

is equal to

$$
g_{y-x}(t-s) 1(t>s), \quad t \in(0, \infty)
$$

where

$$
g_{a}(t)=\frac{1}{\sqrt{2 \pi \beta t}} e^{-\left(a^{2} / 2 \beta t\right)}
$$

So

$$
\begin{aligned}
E_{x} A_{t}^{n} & =n \int_{-\infty}^{\infty} f(y) \int_{0}^{\infty} g_{y-x}(t-s) 1(t>s) E_{y} A_{s}^{n-1} d s d y \\
& =n \int_{-\infty}^{\infty} f(y) \int_{0}^{t} \frac{e^{-(y-x)^{2} / 2 \beta(t-s)}}{\sqrt{2 \pi \beta(t-s)}} E_{y} A_{s}^{n-1} d s d y
\end{aligned}
$$

This proves the following recursion:

$$
E_{x} A_{t}^{n}=n \int_{-\infty}^{\infty} f(y) \int_{0}^{t} E_{y} A_{s}^{n-1} p(t-s ; x, y) d s d y
$$




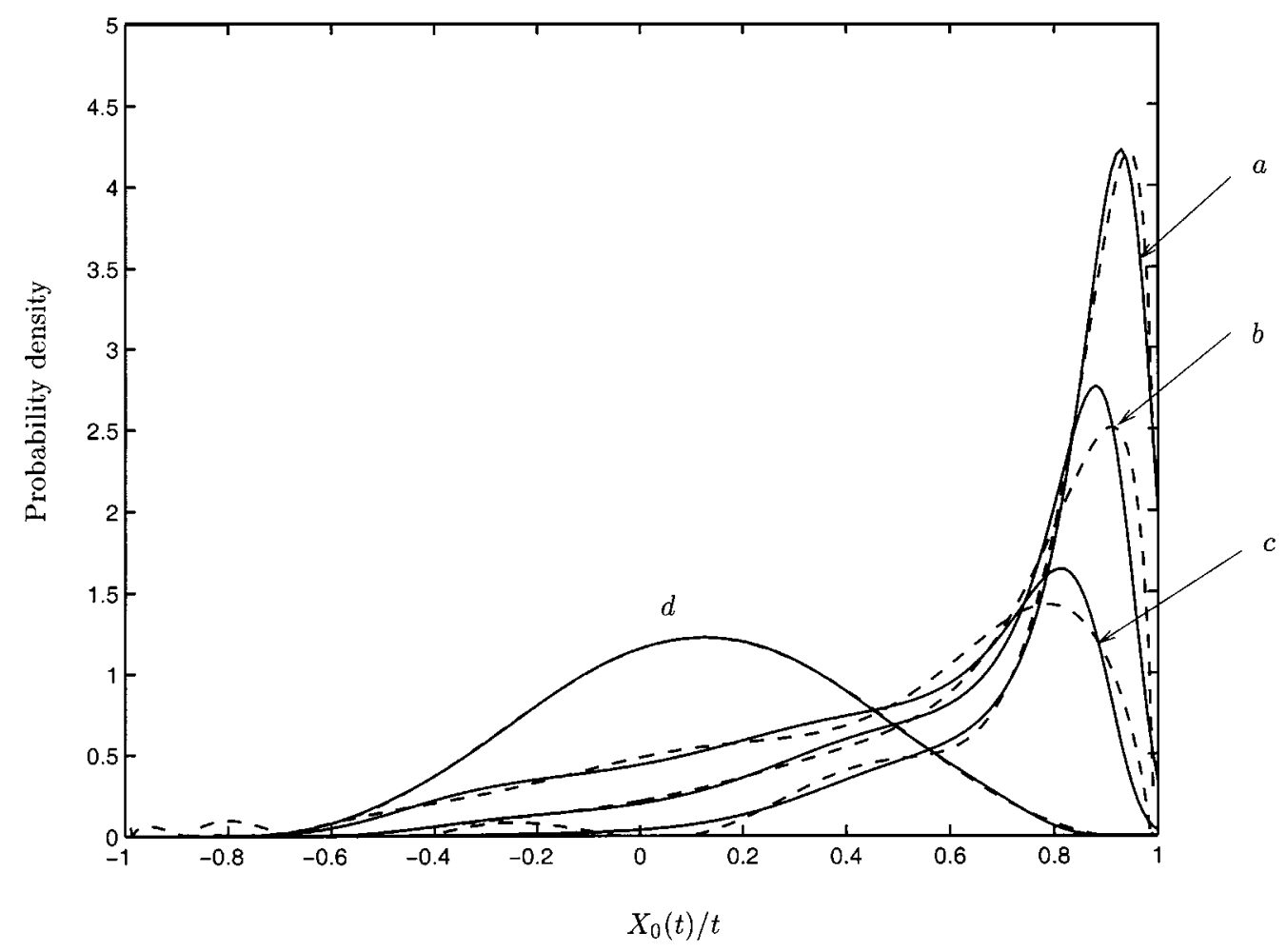

Fig. 1. Probability density of $X_{0}(t) / t$. Zero initial value $x=0$. Solid lines represent the results by a maximum entropy approach while dashed lines denote the Chebyshev polynomial series expansion. (a) $\beta t=1$. (b) $\beta t=2$. (c) $\beta t=4$. (d) $\beta t=18$.

where

$$
\begin{aligned}
p(s ; x, y) & =P_{x}\left(B_{s} \in d y\right) / d y \\
& =(2 \pi \beta s)^{-1 / 2} \exp \left\{-(y-x)^{2} / 2 \beta s\right\}
\end{aligned}
$$

The above recursion has two advantages over the recursion given in [6]. It is simpler in form, and it gives the moments starting from arbitrary $x \in \mathbb{R}$.

\section{APPLiCATIONS}

We apply (8) to find the moments of

$$
X_{x}(t)=\int_{0}^{t} \cos \left(x+B_{s}\right) d s
$$

Note that the cosine can be negative; however, it is not difficult to show that both the functional equation (6) and the recursion (8) also hold for functions that are bounded from below and satisfy (4). From $E_{y} X(t)^{0}=1$, and

$\operatorname{Re}\left\{\int_{-\infty}^{\infty} e^{j y} p(t-s ; x, y) d y\right\}=\cos x \exp \left\{-\frac{1}{2} \beta(t-s)\right\}$

we obtain

$$
\begin{aligned}
E_{x} X(t) & =\cos x \int_{0}^{t} \exp \left\{-\frac{1}{2} \beta(t-s)\right\} d s \\
& =\frac{2 \cos x\left(1-e^{-\beta t / 2}\right)}{\beta} .
\end{aligned}
$$

For the second moment, we obtain

$$
\begin{aligned}
E_{x} X(t)^{2}= & \frac{4}{\beta} \int_{-\infty}^{\infty} \cos ^{2} y\left\{\int_{0}^{t}\left(1-e^{-\beta s / 2}\right) p(t-s ; x, y) d s\right\} d y \\
= & \frac{2}{\beta} \int_{0}^{t}\left(1-e^{-\beta s / 2}\right)\left(1+e^{-2 \beta(t-s)} \cos 2 x\right) d s \\
= & \frac{1}{\beta^{2}}\left\{2 \beta t-4+4 e^{-\beta t / 2}\right\} \\
& +\frac{\cos 2 x}{3 \beta^{2}}\left\{3+e^{-2 \beta t}-4 e^{-\beta t / 2}\right\} .
\end{aligned}
$$

The third moment can be expressed in terms involving $\cos x$ and $\cos 3 x$

$$
\begin{aligned}
E_{x} X(t)^{3}= & \frac{\cos x}{3 \beta^{3}}\left\{136 e^{\beta t / 2}-e^{-2 \beta t}+6 \beta t\left(6+5 e^{-\beta t / 2}\right)-135\right\} \\
& +\frac{\cos 3 x}{30 \beta^{3}}\left\{6 e^{-2 \beta t}-15 e^{-\beta t / 2}-e^{-9 \beta t / 2}+10\right\} .
\end{aligned}
$$

As the order increases, the expressions become more complex. We used a computer program supporting symbolic integration to find the moments up to the 15 th order.

Based on the moments, we used a maximum entropy criterion (cf. [11]) to obtain an approximation for the probability density function (pdf) of $X_{x}(t) / t$. We also used a series expansion involving Chebyshev polynomials for comparison. Two cases were treated as follows: 1) zero starting value $x=0$ and 2 ) a random, uniformly distributed on $(-\pi, \pi)$, initial value $x$ (steady-state regime [7]). In Fig. 1, we present the results of the case of zero initial value for different values of $\beta t$. The results of the steady-state regime are displayed in Fig. 2. In both figures, the solid lines represent calculations with the maximum entropy 


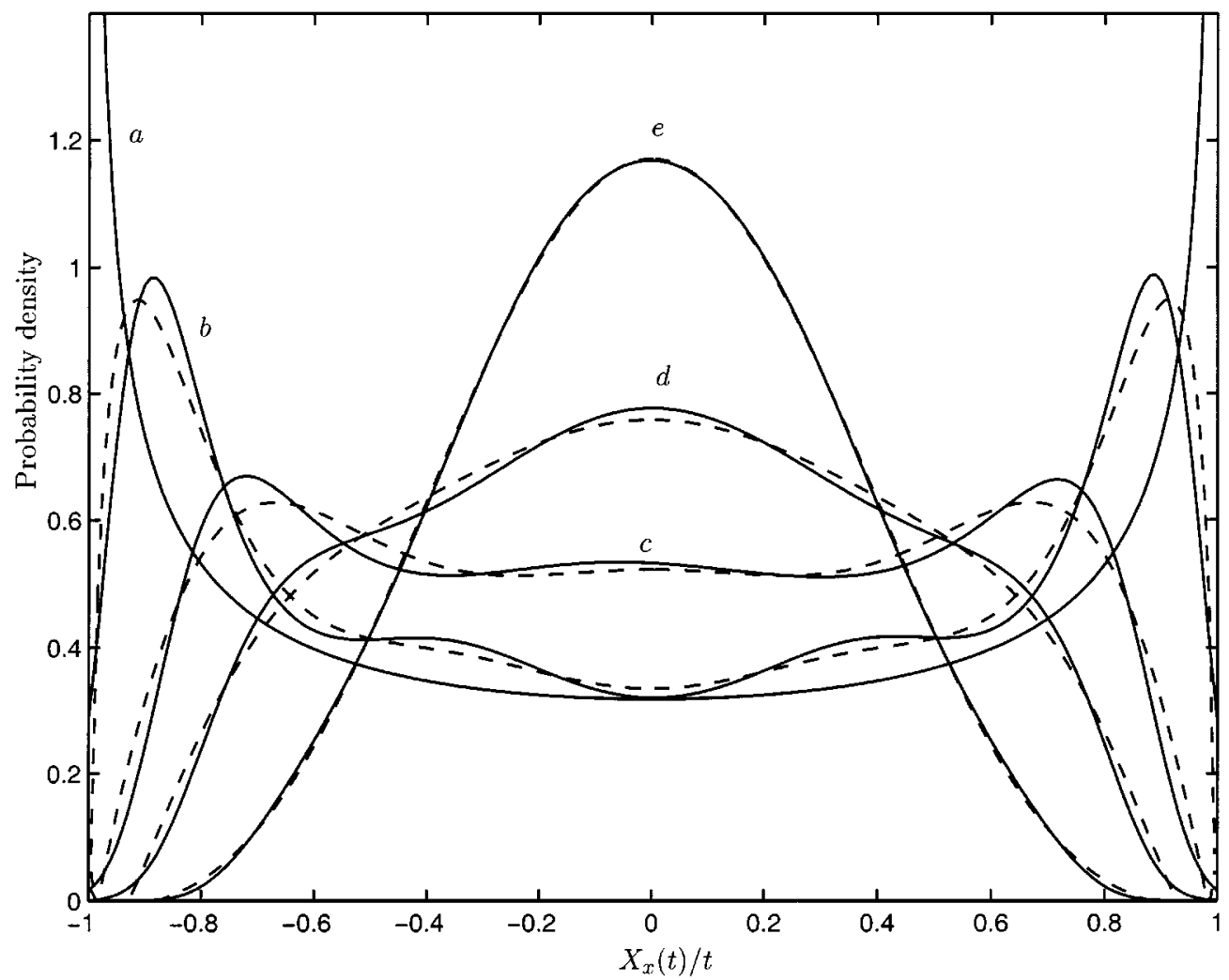

Fig. 2. Probability density of $X_{x}(t) / t$. The initial value $x$ is random, uniformly distributed on $(-\pi, \pi)$ (steady-state regime). Solid lines represent the results by a maximum entropy approach while dashed lines denote the Chebyshev polynomial series expansion. (a) $\beta t=0$. (b) $\beta t=1$. (c) $\beta t=4$. (d) $\beta t=8$. (e) $\beta t=18$.

approach, while the dashed lines represent the Chebyshev polynomial series expansion. Both approaches yield a similar shape of the pdf of $X_{x}(t) / t$. However, the maximum entropy approach seems to converge faster than the orthogonal polynomial representation.

The results for the steady-state regime are found to be in good agreement with previously published results [7]. As one can observe in Figs. 1 and 2, for large values of $\beta t$ (what can be considered as strong filtering), the pdf of $X_{x}(t) / t$ tends to acquire a Gaussian shape.

\section{Conclusions}

A simple recursive formula for the moments of phase noise and its real and imaginary parts is presented. In fact, the recursion is valid for any integral of a function of the Brownian motion provided that the function is measurable, bounded from below, and satisfies (4). The recursion also gives the moments for an arbitrary starting value. Approximate pdf's can be found through a maximum entropy approach or an orthogonal polynomial series expansion. Moments may also be used for the calculation of error probabilities by Gaussian quadrature rules; see [12].

\section{ACKNOWLEDGMENT}

The authors would like to thank the Editor for Optical Communications as well as the anonymous reviewers for valuable suggestions that very much improved this manuscript.

\section{REFERENCES}

[1] G. Foschini and G. Vannucci, "Characterizing filtered light waves corrupted by phase noise," IEEE Trans. Inform. Theory, vol. 34, pp. 1437-1448, Nov. 1988.

[2] I. Garret and G. Jacobsen, "Phase noise in weakly coherent systems," Proc. Inst. Elect. Eng., vol. 136, pp. 159-165, June 1989.

[3] T. Pollet, M. van Bladel, and M. Moeneclaey, "BER sensitivity of OFDM systems to carrier frequency offset and Wiener phase noise," IEEE Trans. Commun., vol. 43, pp. 191-193, Feb./March./April 1995.

[4] L. Tomba, "On the effect of wiener phase noise in OFDM systems," IEEE Trans. Commun., vol. 46, pp. 580-583, May 1998.

[5] R. Taylor, V. Poor, and S. Forrest, "Phase noise in coherent analog AM-WIRNA optical links," J. Lightwave Technol., vol. 15, no. 4, pp. 565-575, 1997.

[6] D. J. Bond, "The statistical properties of phase noise," Br. Telecommun. Technol. J., vol. 7, pp. 12-17, Oct. 1989.

[7] G. L. Pierobon and L. Tomba, "Moment characterization of phase noise in coherent optical systems," J. Lightwave Technol., vol. 9, pp. 996-1005, Aug. 1991.

[8] J. B. Waite and D. S. L. Lettis, "Calculation of the properties of phase noise in coherent optical receivers," Br. Telecommun. Technol. J., pp. 18-26, Oct. 1989.

[9] L. G. C. Rogers and D. Williams, Diffusions, Markov Processes and Martingales, 2nd ed. New York: Wiley, 1997.

[10] D. Freedman, Brownian Motion and Diffusion. Amsterdam, The Netherlands: Holden-Day, 1971.

[11] M. Kavehrad and M. Joseph, "Maximum entropy and the method of moments in performance evaluation of digital communications systems," IEEE Trans. Commun., vol. COM-34, pp. 1183-1189, Dec. 1986.

[12] G. H. Golub and J. H. Welsh, "Calculation of Gaussian quadrature rules," Math. Comput., vol. 23, pp. 221-230, Apr. 1969. 